have a "good old English reputation"; but the pack must be cleverly styled so that the old tradition is presented in conformity with the currently accepted mode.

The method to be used in marketing a product in a specific country is a top-level decision. If the potential market is large enough it is invariably best to establish a subsidiary company. It is certainly more satisfactory to appoint an importing house to act as agent or a company to handle the sole distribution rights than to accept orders from all and sundry.

One of the most unusual management training centres in Europe was described by Clark E. Myers and F. A. Kirby. The school was set up at Lausanne in September 1957 by the Nestlé Alimentana Co., and is designed to provide a nine-months course in business administration for middle management executives from all over the world. The staff consists of American professors recognized in their fields for teaching, publication, consulting and research who wish to continue working in an environment which closely resembles an academic situation.

During the first two years, executives have attended the course from companies in Australia, Belgium, Brazil, Canada, Chile, Cuba, Denmark, Egypt, England, France, Germany, Greece, Holland, Italy, Mexico, Puerto Rico, Malaya, South Africa, Spain, Sweden, Switzerland and the United States. Patterned after the middle-management programme of the Harvard Graduate School of Business Administration, the programme is designed primarily for men whose average age is about thirty-five and who fall within the age range of $30-40$.

Based on the Harvard experience, from which background nearly all the professors are drawn, the case method is used almost exclusively. The major exceptions are several weeks of the programme where the elements of accounting and statistics are taught. The policy is based on the belief that experienced men can achieve a greater sense of stimulation, motivation and involvement by dealing with actual business situations.

One-third of the course is devoted to the quantitative data areas of control and finance (which includes such work as statistics, accounting, index numbers, budgeting and data processing) ; one-third to distribution (including retailing, marketing, sales management and international trade); one-sixth to production, factory management, general management and business policy; and one-sixth to human relations, personnel and labour problems.

The professors teach on three consecutive days either at the beginning or end of the week. The remainder of their time is devoted to writing new teaching materials better suited to an international school. In their employment agreements with the Institut pour l'Etude des Methodes de Direction de l'Enterprise they have agreed to forgo all consulting activities and devote full time to teaching, writing and research for the Institute.

The professors are assisted by research associates. These men have nearly all studied or worked in the United States, and among them have knowledge of nearly every European language. They travel with the professors and assist in research and the writing of new teaching notes and case problems.

Through the development of these materials and cases, the professors gain additional insight into European business affairs, provide better class-room data for the participating executives, assist in publicizing the school and stimulate the interest of European executives in business research and education.

During the first year about two hundred 'pieces of work' were produced. These included new cases, translated cases, technical notes, and a major study of food distribution in seven European countries.

With the increased emphasis on international business, with the coming impact of the Common Market and the free trade area, the directing staff of the Institut pour l'Etude des Methodes de Direction de l'Enterprise believes that such an institution with an international outlook is both desirable and necessary.

Of the many other papers, two of the most outstanding were forecasting and controlling the return on capital involved by J. A. Scott, chief financial executive of Hayeshaw, Ltd., and the effect on quality of administration on technical and commercial efficiency by A. C. Durie, general manager (administration) of Shell-Mex and B.P., Ltd.

\title{
TURBIDITY CURRENTS
}

$\mathbf{I}^{\mathrm{T}}$ was thought for many years that the sediments on the floor of the deep ocean were laid down slowly, the rate of deposition being of the order of millimetres a century. Extensive coring has shown, however, that there are many layers of sand, some with shallow-water fauna, interbedded with the normal deep-water clays and oozes. Turbidity currents, in which a relatively thin layer of sedimentladen water flows rapidly down-slope, have been suggested as a possible mechanism. These currents could deposit such layers of sand in a matter of hours.

When first introduced rather more than twentyfive years ago, the notion of turbidity currents was received sceptically; since thon large velocities have been postulated, but it is difficult to imagine their being produced by such contrasts in density on such gentle slopes. Nevertheless, the idea is now generally accepted by marine geologists, or at least it would appear so from the discussion of the subject held at the Royal Astronomical Society on November 28. Dr. G. E. R. Deacon acted as ehairman.

The evidence supporting the turbidity-current hypothesis was reviewed by Dr. A. S. Laughton. He pointed out that sediment-laden underflows are well known in lakes, being particularly well documented in the case of Lake Mead. It has been estimated that, of the two million tons of sediment deposited in Lake Mead during 1935 48, an appreciable fraction was deposited by turbidity currents extending along the whole length of the lake. The flows are slow, consistent with the slight contrast in density and the gentle slope, but retain their identity for more than a hundred miles.

The classical case of a turbidity current in the ocean is that produced by the Grand Banks earthquake of 1929 which, by breaking a succession of telegraph cables over a period of 14 hours, provided estimates of the velocities reached. These decreased 
from almost $30 \mathrm{~m}$. $/ \mathrm{sec}$. to about $6 \mathrm{~m}$./sec. as the slope decreased from about 1 in 100 to 1 in 1,000 . It seems that this rapid and highly turbulent flow traversed some $1,000 \mathrm{~km}$. and had a breadth of some $300 \mathrm{~km}$. For some geologists these are unimaginably high velocities on this scale, but Heezen and Ewing, who suggested the turbidity-current explanation, have much to support their view. Not only were several of the cables later found to be buried so deeply as to be irrecoverable, but two cores which Heezen later obtained in the area both had thick sand layers of shallow water origin overlying the normal deep sea deposits.

Turbidity currents in lakes and in the ocean were linked by the laboratory investigation of Keunen, who produced similar flows on a small scale by the sudden release of fluid mixtures of water, clay and sand. The important result was that a simple hydraulic formula was found to apply, implying that the effect of the overlying fluid could be neglected, as could the acceleration in the flow. Turbidity currents in lakes, ocean and laboratory were not inconsistent with the simplest formula used to describe river flow. Using this formula, Keunen estimated the depth of the Grand Banks turbidity current to vary between $270 \mathrm{~m}$. and $120 \mathrm{~m}$. during its passage.

Dr. R. Stoneley, in discussing the suggestion that the breakages of submarine telegraph cables, following the Grand Banks earthquake of November 18, 1929 , occurred through the passage of a turbidity current, remarked that the hypothesis has the merit of being more free from ad hoc assumptions than some of the other explanations proposed. The idea deserves further examination from the hydrodynamical point of view. In particular, two aspects have to be considered, namely: $(a)$ whether the turbidity current would spread longitudinally too greatly to be effective; $(b)$ whether the motion of the current would persist over distances of the order of $1,000 \mathrm{~km}$. without being damped out by viscous forces.

Under $(a)$, the longitudinal spread of the mass of water charged with sediment has much in common with the problems of the surge following the breaking of a dam and of the subsidence of a column of water, considered respectively by $R$. F. Dressler, and by W. G. Penney and C. K. Thornhill. A rough calcula. tion based on the work of these authors suggested that the depth of the current as envisaged by Kuenen would be much too great; the hypothesis would be more workable if the current had a thickness of only a few metres. Question $(b)$ depends on the viscous drag of a stream at high Reynolds numbers; tho theoretical and experimental work of G. H. Keulegan on arrested saline wedges suggests a much lower drag coefficient than is appropriate for lower speeds. Keulegan's experiments show that the logarithm of the drag coefficient depends linearly on the logarithm of the Reynolds number, and an extrapolation of this result indicates a thinner turbidity current, with a vertical thickness of about 5 metres. Such a thickness would help to meet the difficulty mentioned under $(a)$.

Further investigations of these hydrodynamical problems are very desirable, and examination is needed of the effectiveness of such a current in transporting and sorting sediments to the degree required.

Two points relating to Dr. Stoneley's contribution were made in the subsequent discussion. It was pointed out that in laboratory experiments the downslope turbulent flow of a fluid under a less dense fluid leads to the formation of a somewhat bulbous 'nose' which travels only a little slower than the body of the fluid. The speed of the 'nose' is considerably less than the long-wave velocity in a perfect fluid. An adequate theory is not yet available. It was also remarked that the diminution of the drag of the sea-bed with increasing Reynolds number may be unjustified if the bottom is hydrodynamically rough. Observations show no decrease of drag coefficient with increasing velocity in the high Reynolds numbers (greater than $10^{7}$ ) of tidal streams.

Dr. T. H. Ellison based his contribution on the work he is doing in collaboration with Dr. J. S. Turner. Their investigation concerns the ventilation of coal mines, but is applicable to the many situations in Nature in which a thin layer of turbulent fluid flows between a boundary and a relatively quiescent underlying or overlying fluid of different density. These include katabatic winds in the atmosphere and what appear to be katabatic bottom-currents in the ocean, as well as the many complicated phenomena observed in estuaries. Turbidity currents are a special case in which the turbulent fluid is made heavier by suspended solids. Some dust storms in the atmosphere are probably similar phenomena.

In the case of turbidity currents it seems that a relatively simple hydraulic theory would describe the observations if the friction and mixing with the overlying fluid could be neglected. It is therefore necessary to make some estimate of the amount of the non-turbulent fluid which would be entrained into the gradually thickening layer of turbulent fluid flowing beneath it. The rate of flow into the lower layer can be expressed as $E V$, where $V$ is a typical velocity of the lower layer. $E$ is the so-called 'entrainment constant', and if the two layers had the same density, $E \simeq 0.08$. In this case the interaction of the two fluids could by no means be neglected. However, $E$ decreases as the hydrostatic stability increases and it is reasonable to assume that $E$ is a function only of the Richardson number, $R i$, which is a dimensionless measure of the stability given in this case by $R i \equiv\left(\rho-p_{0}\right) g h / \rho V^{2}$, where $g$ is the acceleration of gravity, $\rho, \rho_{0}$ are the densities of the lower and upper fluids, and $h$ is the depth of the lower fluid. Two sets of experiments have been made to determine $E$ in relation to $R i$. The results are scattered but agree that for $R i>0.8$, which is the case in turbidity currents, then $E$ becomes very small. The interaction between the two fluids is much reduced by the strong hydrostatic stability, and it is for this reason that a turbidity current can retain its identity for a long period and that the flow can be described by a simple formula applicable to river flow. Ellison's results are therefore broadly similar to those based on Keunen's work and support his conclusion: turbidity currents are compatible with our present knowledge of turbulence in stratified fluids.

The discussion which followed showed almost complete acceptance of this point of view ; those against the turbidity-current hypothesis were either absent or silent. This is not to say that no problems remain. We know little of the ways in which turbidity currents are started or of the factors which determine whether water laden with sediment will behave as a heavy fluid or as a sloppy sort of solid. How often do turbidity currents happen? Were they stronger and more frequent during Ice Ages, and could they then have cut submarine canyons?

They presumably happen so infrequently that they make no contribution to the economy of the bottom water. For the same reason there is little hope of direct observation, although bathyscaphists report. 
that they have started mudslides when landing on steep slopes. Attempts to start them by using explosives in canyons have had little success. Altogether, considering its potential importance in the formation of abyssal plains and the structure of some sedimentary rocks, the turbidity-currents hypothesis seems to have had little influence on marine geologists. It is surprising, for example, that following the classical Grand Banks turbidity current only two cores have been collected from the area and they apparently during borrowed time from a cruise with other objectives. Both these cores, taken some $20 \mathrm{~km}$. apart, have sand layers at the surface. Below this, each has further layers of sand, but there is so little correlation between them that one can only speculate as to the horizontal structure. Taking closely spaced cores is technically difficult, time. consuming and expensive, but in some areas the expense would surely be justified.

H. Charnogk

\section{THE BRITISH COUNCIL}

\section{REPORT FOR 1957-58}

$\mathrm{T}$ $\mathrm{HE}$ annual report of the British Council for 1957-58* includes a general survey of the year and is preceded by an article on the printed word by Sir Charles Snow, which stresses the importance of the work the Council is doing in this field on an expenditure of only $£ 17,000$, but urges the need for expansion. The report is accompanied by a separate account of the Council's work for visitors and students from overseas. More than half the report is occupied by appendixes listing the officers, executive committee, advisory committees and panels, with their membership, and giving particulars of university interchanges, courses and study tours, etc., arranged by the Council in the United Kingdom or overseas, exhibitions and publications, and an analysis of the estimates and accounts.

The increase in the Government grant for 1957-58 to $£ 3,378,271$ out of gross expenditure of $£ 3,867,899$ enabled the Council to start improving the supply of English teachers and teaching material for overseas and other work in accordance with Government decisions contained in the White Paper on Overseas Information Services. Further activities will be possible in 1958-59 with the increase of nearly $£ 650,000$ on the original estimates for $1957-58$. For this year the Council is recruiting, or helping to recruit, on improved terms, for about seventy overseas teaching posts in English in schools, training colleges and universities, chiefly in Asian countries. It is also co-operating closely with a unit established by the Ministry of Education to assist in placing satisfactorily the returning teacher. Much is being done abroad to help overseas teachers of English, and the Council has also been closely associated with the new School of Applied Linguistics in the Univer. sity of Edinburgh, to which one of its most experienced English-teaching specialists is being seconded. The Council is contributing $£ 5,000$ towards the establish. ment of an Overseas Visual Aids Centre to further increased and more efficient use of visual and audiovisual aids in formal and informal education overseas.

The specialist tours arranged by the Council include an advisory unit at the request of the Burmese Government of Prof. H. F. Humphreys and Mr. W. J. Deacon to examine and report on the state of education in Burma, a visit to Turkey of thirteen British surgeons, headed by Sir Clement Price Thomas, and tours of Prof. C. Wells to Pakistan, Burma, Thailand, the Philippines, Australia and Canada, to advise on surgical techniques and radiological services, and of Sir Alister Hardy to Pakistan, Thailand, Hong Kong and Japan to inspect oceanographic institutions. More than 1,800

* Rritish Couneil. Annual Report 1957-1958. Pp. vi +111+8 plates. (London: British Council, 1958.) visits of scientific specialists to and from Britain were assisted by the Council in one way or another in 1957-58, representing $35 \mathrm{per}$ cent of the total for all subjects and professions. In numbers this repre. sents $42 \cdot 6$ per cent out of 4,902 visitors to the United Kingdom under the auspices of the Council, compared with 18.5 per cent in social studies, 14.8 per cent in education and 10.1 per cent in medicine; for 1951, the corresponding figures were $23.5,15$, 14.5 and 10 per cent, respectively. There has been a striking growth in recent years of the Council's responsibilities as agents for the United Nations Specialized Agencies, the Colombo Plan, the Baghdad Pact and other international agencies offering training in the United Kingdom, and in 1957-58 1,012 such visitors were cared for in the United Kingdom by the Council, compared with 191 in 1950-51. About $£ 380,000$ a year is administered by the Council for international and overseas organizations.

The fifteen short specialist courses arranged annually included one on the economic problems of developing countries, for senior officials and administrators, and in 1957 study tours were arranged for 67 groups, many from British Colonial territories, while in the autumn of 1957, 300 Soviet students and young people were invited to visit the United Kingdom for periods of three weeks. This programme has made considerable progress on an exchange basis with the co-operation of leading student and youth organizations in the United Kingdom, while the Council has also placed a number of postgraduate Soviet scholars in British universities and promoted exchange visits of teachers of English and Russian to summer schools in the United Kingdom and the U.S.S.R.

The number of overseas students in the United Kingdom rose in 1957 to 35,000 and is now about 38,000 , less than a third of whom are at universities. In $1957,7,782$ students were met on arrival, 4,644 were assisted to find permanent accommodation, 386 becoming permenent residents in the Council's own residences, which also provided transit accommodation for 1,692 students. New premises were acquired during 1957-58 in Hull, Leeds, Liverpool and Nottingham. Some 13,259 overseas students attended British Council vacation and week-end courses and study visits, and private hospitality was arranged for 5,481 students. Travel grants to university teachers on study leave and to postgraduate workers totalled thirty-six (twelve from Australia) for visits to the United Kingdom and four for visits from the United Kingdom, and under the younger research workers interchange scheme twelve visited the United Kingdom and twenty-five from the United Kingdom visited six European countries. 